\title{
Super Global Projects and Environmentally Friendly Technologies Used in Space Exploration: Realities and Prospects of the Space Age
}

\author{
Sergey Krichevsky \\ Doctor of Philosophical Sciences, Professor, Institute of the History of Science and \\ Technology named after S.I. Vavilov RAS (Moscow, Russia) \\ E-mail: svkrich@mail.ru \\ ORCID: 0000-0002-1094-7770
}

The $60^{\text {th }}$ anniversary of the Space Age is an important intermediate finishing point on the way of a man and the whole humanity to space. Along with the outstanding achievements, there are a number of challenges and contradictions in space exploration due to the aggravation of the global crisis on Earth, low efficiency and the backlog of space research in the transition to a new technology based reality and clean technologies. Both the international astronautics and the space exploration area nowadays face difficulties in choosing a new paradigm and a development strategy that is becoming even more complicated due to the current unstable and turbulent situation on Earth. The article reveals the optimistic scenario of further space exploration, as well as the methodological and practical aspects of new projects and technologies. The periodization of the Space Age history has been conducted. It has been also proposed a new classification of the "space" phenomenon due to concretizing the concept of "global" in the form of a three-scale structure encompassing the following levels: 1) planetary global; 2) super global; 3) universally global. The notion of "super global space exploration project" has been introduced.

The concept of further space exploration is proposed, which includes four interrelated super global projects:1) Earth Protection System from Asteroid and Comet Threat; 2) Moon Exploration; 3) Mars Exploration; 4) Cosmic Humanity. Since the humanity is embarking on the practical implementation of these super global projects, it is urgent to make a transition towards a new technology based order, as well as up-to-date technologies. A couple of ecological projects and space exploration technologies of the $20^{\text {th }}$ and $21^{\text {st }}$ centuries have been exemplified and analyzed. It has been also worked out the list of new environmentally friendly space technologies and projects. The research makes an emphasis upon a great potential of clean and green technologies within space exploration area, but it states the necessity of controlling and managing the transition towards such environmentally friendly options. A new wave of space awareness and exploration is currently arising in the world, whereas the boundaries of space activities are being constantly expanding. Consequently, the humanity is bound to reach a new level of space study by working out and implementing the global strategy aimed at synthesizing new super global programs and efficient eco-technologies and projects in the paradigm of balanced sustainable "green" development on Earth and in the Universe. To achieve these objectives successfully there is a need for anticipatory philosophical reflection and interdisciplinary examination of recent projects and technologies in space exploration in order to study and correct them.

Keywords: space activity, Space Age, space exploration, environment, super global projects, sustainable "green" development, clean technology, environmentally friendly technologies and projects.

(C) Krichevsky, Sergey, 2018 
Received 18 June 2017; accepted 10 August 2017

Philosophy and Cosmology, Volume 20, 2018: 92-105

DOI: 10.29202/phil-cosm/20/8

\section{Introduction}

The $60^{\text {th }}$ anniversary of the Space Age ${ }^{1}$, which was celebrated worldwide in 2017, is an important intermediate finishing point on the way of humanity to space. It is also the moment of truth for the analysis of the results, the current situation and the space exploration prospects, its impact on terrestrial civilization aimed at survival and development of a man and a society ${ }^{2}$.

Over the past years, the significant results in the exploration and use of outer space for the development of science and education have been achieved, as well as the solutions of some applied issues within the branches of economy, defense, environmental protection have been found.

At the same time, there are a number of complex problems and contradictions in space exploration due to the aggravation of the global crisis on Earth, the backlog of the space activity area in the transition to a new technology based order, efficient and clean technologies ${ }^{3}$.

During the last 60 years in the society there has appeared a transition from absolute euphoria in designing, perception of space activities and forecasting its results to awareness of the problems and restrictions, to economic pragmatics and growing criticism of the space activity area that, despite all its outstanding achievements, significant results and huge development potential, increasingly lacks effectiveness compared to other branches of human activities in the $21^{\text {st }}$ century. Among the reasons of such a tendency one can single out the peculiarities of the space activity area itself, the internal and external aspects, including the problems and restrictions caused by the features of the space projects and technologies. ${ }^{4}$

In the beginning of the $21^{\text {st }}$ century the world community faced the crisis of goal setting and the strategy of space activities. That crisis has not been overcome yet, but a couple of new encouraging ideas, projects and technologies have recently appeared. They particularly include two up-to-date mega projects: (1) Elon Musk's Mars Colonization Project (2016) and (2) Igor Ashurbeyli's Space Nation of ASGARDIA Project (2016-2018) [SpaceX Corporation Website; Website "Asgardia — The Space Nation"; Krichevsky, 2017a].

The new space exploration strategies, the space projects and technologies of the $21^{\text {st }}$ century, their development, working out, selection and implementation on the basis of scientific

${ }^{1}$ The Space Age began on October 4, 1957, when the first artificial Earth satellite was launched into the near-earth orbit in the USSR. In the first half of the $20^{\text {th }}$ century it was preceded by papers, the space exploration projects of Konstantin Tsiolkovsky, Friedrich Zander and other pioneers of space travel. See at the works of Tsiolkovsky (1989); Zander (1988).

${ }^{2}$ Here is a brief overview of the results of the author's research in the Institute of the History of Science and Technology named after S.I. Vavilov RAS in 2013-2017 on the history of space technology and activity, the environmental aspects of the technology evolution, as well as on a newly planned research paper Environmentally Friendly Aerospace Technologies and Projects of the 20-21 st centuries: History, Trends, and Prospects (State Registration № 0002-2018-0003).

${ }^{3}$ These topical issues were discussed at the Symposium The 60 $0^{\text {th }}$ Anniversary of the Space Age and New Space Exploration Projects at The 52d Scientific Readings devoted to the Memory of K.E. Tsiolkovsky on September 19, 2017 in Kaluga, Russia.

${ }^{4}$ See [Space Age, 1970; Gatland, 1986; Grishyn, 1987; Vlasov, 1999; Mihailov, 1999; Krichevsky, 2012-2017; Galimov, 2010; ROSCOSMOS Website; NASA Website]. 
approaches towards goal setting, analysis, assessment according to the gained experience under relevant and appropriate approaches, criteria, prediction methods, futurology and other related issues are of great significance these days. ${ }^{5}$

Both the international astronautics and the space activity area face difficulties in choosing a new paradigm and a development strategy, which is also complicated by the current unstable and turbulent situation on Earth.

Although the current research reveals an optimistic scenario for the further development of outer space, it is obvious that it cannot avoid sharp criticism from the supporters of the so-called priority solution of the Earth's problems, minimization of space activity, its limitation with near space exploration, etc.

Astronautics is technologically featured and structuralized. It is impossible to sort out the problems of improvement of safety and space activity efficiency without moving towards the direction of such a new technology based mode and mass application of up-to-date technologies in particular.

To resolve the topical problems of contemporary astronautics and the space future of humankind successfully, all scientific and technical activities ought to correlate with philosophical reflection and interdisciplinary examination of new projects and space exploration technologies aimed at their study and modification including the Earth's realities.

\section{Basic Concepts and Definitions}

Space Age - a new time period in the history of the human civilization since 1957, encompassing such important properties, achievements, opportunities, challenges, risks and prospects which are crucial for the development of space technologies and activities in today's world and in the future of mankind.

New projects - are new "big" projects, so-called megaprojects, global projects, "super projects", "super global" projects of space environment exploration (research and utilization) in such fields as astronautics and space activity.

There are various definitions and interpretations of the phenomena "megaproject" and "global project". These terms are often used within the field of space environment exploration as well. The concept of a megaproject is usually associated with space-time characteristics (significant dimension, multi-year implementation period) and cost rate (more than $\$ 1$ billion), whereas global projects are of a planetary extension, but are not limited by it due to their complex impact on various areas of society and the environment.

The notion "global" can be also multi-interpreted - encompassing the sense of "planetary" and the "the whole globe" idea and extended to the sense of "universal" and "the entire Universe" interpretation ${ }^{7}$.

In an attempt to develop Ilya Kasavin's approach (2015), we are supposed to determine the concepts of megaprojects and global projects as "super goals" and "super objectives", and define the most powerful among them as "super projects". Such "super projects" of

\footnotetext{
${ }^{5}$ See [Galimov, 2010; Global, 2013; Cosmonautics, 2010; Krichevsky, 2012, 2017; Piloted, 2006; Predicting, 2008; Rozin, 2017; Futurology, 2013].

${ }^{6}$ The methodological approach to the analysis of megaprojects and global projects, as well as the description of the experience of their implementation on Earth were published by Ilya Kasavin [Kasavin, 2015].

${ }^{7}$ Arkady Ursul and Tatyana Ursul's papers reveal rather vague and even contradictory definition of the idea of "global" with reference both to the planetary scale and beyond it. See, for example, in one of their articles on the issue of global space revolution [Ursul, 2017].
} 
space activities should be interpreted as "super global" programs of space exploration (for example, the futurological project of human settlement outside Earth aimed at creating permanent space humanity).

We mean to propose a new structure and classification of physical space and activity space phenomena, needed to designate new time periods of the Space Age and the space exploration projects. We are going to use the generally accepted concept of "global", which, from our point of view, is expedient to be concretized and interpreted as a three-scale structure encompassing three levels that are as follows: 1) planetary global; 2) super global; and 3) universally global scale/level.

Global or planetary-global is the entire planet scale of the Earth's space. It is expedient to introduce a new term "super global scale" (or "super global level") that contingently corresponds to the size of the solar system and our Galaxy to distinguish between the concepts of "planetary global scale" of Earth and terrestrial humanity and the following scales (levels). We tend to denote the following limited scale (level) as universally global, corresponding to the whole Universe 8 .

Super global projects are the largest "super projects" encompassing the features of "mega" and "globality", but exceed them in scale, space, time, cost and the set of impact factors on the society, the Earth's and the space environment, etc. They are, in their core, super global, that means that they are such super planetary programs that go beyond the physical, geographical space of the Earth, the social space of terrestrial humanity, planetary connections, effects, consequences, etc. within the space of the Solar system and our Galaxy.

In addition to reaching and going beyond the global, planetary bounders and also due to their huge "target" potential, the super global projects could be featured as both utopias and attractors with some synergetic effects. Within the scale, such projects can fulfill the role of a so-called "superhighway" 9 for organizing and realizing the sustainable development of mankind. Such projects, as well as their properties, features, impact factors, consequences, including negative and remote ones, have not been sufficiently studied yet.

New technologies are new and up-to-date "means to meet the goals, set by society" [Lem, 1968: 23].

Technology - "a set of methods and means of obtaining, processing or recycling raw materials, semi-finished products or goods, carried out in various industry fields, in construction area, etc." [Preliminary, 2014: 8].

The best available technology is "the technology of goods production, work performance, social services provision, determined in accordance with the modern scientific and technological achievements and the best combination of the criteria for

${ }^{8}$ In this article, we would rather dwell on the definition given above because this structure and classification could be continuously detailed. For example, it is possible to single out a few additional scales (levels) of space and space activity such as "solar global" (within the solar system) and "galactic global" (the Milky Way as the system within our Galaxy). Furthermore, the galactic-global scale has already become relevant for the space expansion of our civilization and the technosphere, in particular, due to the "old-dated" but rather active project "Voyager" (NASA, USA). In fact, the spacecraft Voyager-1 and Voyager-2, launched in 1977, went beyond the limits of the solar system in 2013-2014 and are currently flying within the interstellar space of our Galaxy. See at: [Krichevsky, 2017; Where are the Voyagers, 2017].

${ }^{9}$ Here is meant the general concept of "superhighway of sustainable development" according to Arkady and Tatiana Ursul's research [Ursul, 2012]. Meanwhile, the current article describes space activities and space exploration issues aimed at leading sustainable development of mankind, according to the universal evolution of the Universe. 
ensuring environmental protection policy, provided that it is technically possible to use it" [Preliminary, 2014: 4].

"Green" technologies tend to combine sometimes fundamentally different approaches, they serve as an outlet to a trajectory of a clean growth, characterized by a higher resource efficiency and "resilience" to unfavorable external distractors" (cited in [Pakhomova, 2012: 9].

Clean technology ("cleantech" as a shortened form) commonly refers to any process, product, or service that reduces negative environmental impacts through significant energy efficiency improvements, the sustainable use of resources, or environmental protection activities.

It should be noted that any projects and technologies in their nature, purposes and properties could be technical, social, etc.

In terms of space and implementation goals, the field of space environment exploration (research and practical use) is contingently divided into 2 directions: 1) "to Earth" (in the interests of development and security on Earth); 2) "into space" (expansion beyond the Earth). The US National Aerospace Agency (NASA) organizes and accomplishes its space activities in accordance with such logic and structure [NASA Website].

Environmentally friendly technologies and projects correspond to eco-standards or outstrip them, do not affect the environment, life and health of people in a harmful way, or have less negative impact in comparison with other programs. These include clean, "green" technologies, the best available technologies with the emphasis on those properties and features of the technologies that are not applied with their full life cycles. There is a complex conflict between inherited ("dirty", "black", etc.) technologies, the best available technologies and clean, "green" technologies. ${ }^{10}$

\section{Time Periods of Space Age}

The history of Space Age could be contingently divided into three time periods:

The $1^{\text {st }}$ time period initiated the beginning of space activities in the 50-60s of the $20^{\text {th }}$ century, when the first artificial earth satellite was launched into a near-earth orbit (October 4, 1957), including the first flight of people into space (Yuri Gagarin, USSR, April 12, 1961), the first astronauts' flights into outer space (Alexei Leonov, USSR, March 18, 1965), the first flights of people (Moon expeditions, USA, 1968-1969), the first human-done step foot on the extraterrestrial celestial body - the Moon (Neil Armstrong, USA, July 21, 1969).

The $2^{\text {nd }}$ time period featured the formation of the space activity sphere as an important and full-fledged field of social interaction activity, national economies and the global economy of the Earth's civilization (from the 1970 s of the $20^{\text {th }}$ century to the 2010 years of the $21^{\text {st }}$ century), including the constant stay of people on the manned space stations outside the Earth on the near-earth orbit.

The $3^{d}$ time period generated the implementation of super global space exploration projects, super global industrialization and post industrialization of space activities aimed at setting safety and development of mankind on Earth and outside the Earth, exploring extraterrestrial resources and objects, further expansion into space (starting from the 2020s of the $21^{\text {st }}$ century) to Moon, Mars, etc., and the formation (in the future) of stations, settlements, Cosmic Humanity.

In the leading "space" countries (Russia, USA, EU, China), the largest space corporations (SpaceX and others) there are a couple of current and under further implementation strategies, programs and projects for long-term space exploration, including international

${ }^{10}$ See [Krichevsky, 2014-2016]. 
programs and projects (for example, the megaproject of the manned International Space Station $^{11}$, flying in the near-Earth space since 1998).

The number and potential of such strategies, programs and projects, as well as the amount of funding from public and private sources are increasing, and in the $21^{\text {st }}$ century, it naturally goes into a new quality.

The core point of the "contemporary state" of the Space Age is the change of its historical time periods: the finishing of the $2^{\text {nd }}$ and moving towards the $3^{\text {rd }}$ stage, the beginning of the transition to the practical implementation of super global projects of space exploration. The agenda of the countries, leading in the field of space activities, their space agencies and giant space corporations, presupposes the initiation of new large-scale projects aimed at exploring Moon, Mars, and other space objects.

\section{Super global projects of space exploration}

The concept of further space exploration is proposed, encompassing a number of interrelated super global projects. Among a great number of newly initiated space exploration projects, we should single out and emphasize on four super global programs, which are as follows: 1) Earth Protection System from Asteroid and Comet Threat; 2) Moon Exploration; 3) Mars Exploration; 4) Cosmic Humanity. They are arranged in such an order that reveals increasing complexity and duration of possible program implementation. Meanwhile, the very first project is the only one, dealing with "to Earth" research direction, the rest three programs consequently refer to "into space" studies. These projects have been known for a long time now and they have been widely discussed in the scientific community and the space activity and social fields so far, but the thing is that at present these projects' novelty exactly refers to the active transition to the practical implementation and application of all corresponding ideas and theses proclaimed earlier.

In fact, each of these super global programs encompasses a great variety of options, scenarios, specific projects (including relevant projects covering energy, transport, robotic, environmental and a set of nano-, biological, informative, cognitive, social (NBICS) and other systems, clusters and aspects) within which it is necessary to choose the most relevant (the best) for the further successful implementation.

These four super global projects, described above, are in tight and complex relationships with each other that require further consideration in the overall strategy and specific logistics, including legal, political, economic, technological, social, environmental and other aspects.

The implementation of super global projects is the super task of humanity at the new stage of the Space Age on the way to its $100^{\text {th }}$ anniversary (in 2057), during the entire $21^{\text {st }}$ century and even later.

According to the logic of deduction, super global projects tend to be an ideological and organizational framework and the basis for an ultra-long-term strategy for the space environment activity of mankind.

${ }^{11}$ The project of the International Space Station is sometimes called a super project, it is the most expensive in the history of space exploration (over $\$ 140$ billion has been already spent on it) and has united a number of leading space countries of the world for further cooperation. This "transitional" super project features some properties of super globality and precedes complete super global programs, as it fulfils an important mission aimed at preparing humanity for the organization and implementation of super global projects. 
At the present moment, humanity faces a difficult choice: how, in what way, according to what strategy and logistics, using what resources and paces of development the process of the super global project implementation of space exploration ought to be initiated.

There are a number of crucial issues that are in need to be solved. They are as follows:

1. Priority setting process.

2. New "rules of the game" within the field of space environment activities.

3. International cooperation establishment.

4. Economic mechanisms and resources.

5. The transition towards a new technology based model and fundamentally modern technologies.

In addition, it being known that it could be possible only under required conditions and the unification of human efforts and world resources on the Earth.

\section{Earth Protection System from Asteroid and Comet Threat}

The target is to protect humanity and Earth from an asteroid and comet attack.

At the end of the $20^{\text {th }}$ century and in the $21^{\text {st }}$ century, new scientific data on the threat of collisions of asteroids and comet nuclei with Earth, which might end up destroying our civilization partially or completely, was acquired. The probability of new threats and risks is being forecast. It was in 2000-2007 when Anatoly Zaitsev firstly initiated the project Citadel aimed at active protection of our planet. Therefore, more and more surveillance systems for monitoring such dangerous objects are being constantly fixed in today's world. ${ }^{12}$

In fact, setting and applying a full-fledged active Earth's protection system require dealing with and sorting out a number of complex legal, military and political, technical, economic and environmental issues in the format of an international project and cooperation under the auspices of the United Nations.

It is believed that the beginning of the deployment and operation of the active Earth Protection System will become possible in the 2020-2030s of the $21^{\text {st }}$ century, and the fullscale active protection of mankind, the biosphere and the whole Earth will be established starting from the $22^{\text {nd }}$ century (according to scientific predictions) [Krichevsky, 2012]. In the long term, the Earth Protection System should use and include the Moon and the entire protection space in $\mathrm{R} \sim 1$ million $\mathrm{km}$ from Earth.

In the future, it is possible to create such a system on Mars aimed at the protection of bases and the settlements on this planet, and also as a far-away echelon of Earth protection.

\section{Moon Exploration}

The project objective is to include the Moon in the mankind activity and consider it as a productive field for doing research, using extraterrestrial natural resources, resettling the population, developing and working out modern technologies, designing and testing new high-tech appliances, safety systems and programs for the enhancement of our civilization, as well as further space environment expansion, including Mars exploration, etc.

Nowadays there are a lot of popular modern projects and well-known active proponents of the Moon exploration such as Erik Galimov, Boris Chertok, Elon Musk and others. It is advisable to refer to the experience of the Moon research projects of the $20^{\text {th }}$ and $21^{\text {st }}$ centuries, especially to the Apollo program (USA), initiated in the $1960-70$ s of the $20^{\text {th }}$ century, as well as the practice and background of a number of projects for the Mars exploration. ${ }^{13}$

${ }^{12}$ See [Asteroid and Comet Threat, 2010; Zaitsev, 2007; Krichevsky, 2012].

${ }^{13}$ See [Galimov, 2010; Cosmonautics, 2010; Piloted, 2006; Website of the S.P. Korolev Rocket and 
One of the crucial challenges is the choice of priorities between the Moon and Mars exploration initiatives. The thing is that since the beginning of the $21^{\text {st }}$ century, there have been a number of publications, discussions and decisions, including the highest state levels in Russia and the USA, proclaiming the idea of the immediate Mars mission because of the lack of prospects of the Moon research direction. However, in recent years there has been a deep understanding of the need to move towards the outer space throughout the Moon, its environment exploration as a perspective addition to all mankind activities on Earth.

To join and engage the Moon into the human communication and economy areas, as well as into the structure of the Earth's defense system from asteroid and comet attack threat, appears to sound quite logical and justified due to the outer space characteristics and other factors (the Moon is a natural satellite of the Earth at a distance of $\sim 400$ thousand $\mathrm{km}$, in the gravitational field of the Earth, which affects in $\mathrm{R} \sim 920$ thousand $\mathrm{km}$ ).

In the $21^{\text {st }}$ century, we are awaiting for developing fundamentally new technologies aimed at ensuring the safety of human existence within the Moon environment; establishing reliable and effective communication and interaction with the Earth; conducting scientific and industrial activities based on local resources, a space station and human settlements on the Moon; initiating the overall use and environmental protection under the Moon's natural peculiarities, as well as near-Earth and near-Moon space features.

\section{Mars Exploration}

The purpose is the realization of the idea of a reserve planet for the humanity of the Earth in the solar system.

In 1920, one of the first projects for the Mars exploration was been initiated by Friedrich Zander under the motto "Forward, to Mars!" [Zander, 1988]. In the 1960 s of the $20^{\text {th }}$ century, the project of the Mars manned space complex was being designed under the scientific supervision of Sergei Korolev. At the present moment there are a number of modern programs of the Mars colonization, including Russian and Americal projects. ${ }^{14}$ There is also a well-known Chinese project referring to the idea of the resettlement of at least 1,000 people to Mars with the prospect of the so-called "back" settlement of the Earth after a possible future global catastrophe, as a result, the entire Earth is likely to be populated by the Chinese [Cosmonautics, 2010].

In 2016, Elon Musk announced the launch of a megaproject of the Mars colonization on resettlement of 1 million human beings until the end of the $20^{\text {th }}$ century. But next year (2017), an absolutely new vision of technical, economic, social and other problems' complexity adjusted Elon Musk's project, according to which the Moon colonization mission is taken into account as the first project stage (see at: [SpaceX Corporation Website]).

The main problem refers to the dangerous effects on human life and health of a long space flight to Mars, the environmental factors of this planet, and also other conditions and the consequences of a permanent stay there. To solve the stated issues, a lot of fundamentally new technologies for protecting a person and ensuring common living conditions using local resources must be developed. It seems to be even more complex to implement and expensive to design the complex of social, ecological, economic and bioethical problems of this planet exploration, as well as the successful organization of the social and ecological environment on Mars and the efficient interaction of the Martian colony with civilization

\footnotetext{
Space Corporation Energia; ROSKOSMOS Website; NASA Website; SpaceX Corporation Website].

${ }^{14}$ See [Piloted, 2006; Website of the S.P. Korolev Rocket and Space Corporation Energia; ROSKOSMOS Website; NASA Website].
} 
on Earth. The proposed projects on Mars terraforming, including physical and biological technologies aimed at creating an atmosphere and ecosystems similar to those existing on Earth, are unlikely to solve the current problem due to the characteristics of Mars, planetary and external processes. It is expected to "fit" completely into the nature of Mars, to use resources, transform its environment taking into account environmental restrictions and the wild nature of space [Krichevsky, 2012]. Therefore, the process of Mars exploration is likely to be more complicated and time-consuming than the Moon colonization mission, and it is supposed to be carried out using the experience and technologies practiced within the Moon's environment.

\section{Cosmic Humanity}

The super global project of creating Cosmic Humanity is considered to be the most powerful and long-term of all possible space exploration projects. All super global projects described above fully correspond its content.

The target of this project encompasses the creation of a new humanity outside the Earth's environment aimed at surviving and developing the united humanity (in case of the loss of our planet) and future expansion.

It was 100 years ago when Konstantin Tsiolkovsky put forward the idea of the location of humanity beyond the Earth's atmosphere, thus, the concept of the space mankind was firstly proclaimed.

According to our conception, the phenomenon of Cosmic Humanity is defined as: 1) the humanity living on Earth, feeling, realizing, comprehending its "out of space" origin, the relationship with the Universe and its space destiny; 2) the humanity living on Earth, providing space activities aimed at exploring and using the outer space for survival and self-development; 3) the humanity living on Earth and beyond the Earth's environment, within the solar system, preserving the Earth and mastering the Universe for the future survival and self-development; and 4) the humanity, settled and dwelling in space. The four stages, determined above, are the ascending levels of the evolution and creation of Cosmic Humanity as a complex process of synthesizing properties and expanding the space-time existence and being of man and society, i.e. the entire human civilization on Earth, then beyond the Earth's atmosphere, in the Solar System, the Galaxy, and in the Universe. At present, the humanity is on the point of its moving from the second to the third stage. In the process of this evolution, a complex transformation of man and society takes place. The human settlement outside the Earth's environment is considered as the most significant task of mankind, the strategic goal of manned astronautics and the space exploration area. The generally global meta-goal setting process is the justification of the necessity of Cosmic Humanity aimed at: 1) surviving and developing of mankind within the "Earth+" space (i.e. Solar System + Galaxy + Universe) in the future; and due to the fact that 2) Cosmic Humanity features evolutionary mission to actively manage the evolution process, i.e. to change essence of man, mankind and the entire Universe [Krichevsky, 2017a].

Since 2016, it has been implemented the Space Nation of ASGARDIA mega project as an acting model, a prototype and the core point of space mankind. In 2017, the ASGARDIA Constitution was adopted, the first satellite Asgardia-1 was launched into a near-earth orbit with a height of $\sim 500 \mathrm{~km}$, becoming the state territory with information about the state and its citizens on the satellite board. On the day of January 1, 2018, ASGARDIA program contained $\sim 150,000$ citizens representing $\sim 200$ countries around the world. At the moment, the formation of authorities is underway, followed by an appeal from ASGARDIA to the UNO with the request for an official recognition of the new independent state. 
In fact, other scenarios of the Cosmic Humanity establishment are also probable: the classical one encompassing the preliminary unification of mankind on Earth, proclaimed by Konstantin Tsiolkovsky, the projects Neo-Humanity and Avatar, put forward by Dmitry Itskov (2012-2013), as well as the synthesis of scenarios. ${ }^{15}$

$* * *$

The super global projects are brand new and additional to the already implemented space activities (e.g. monitoring of the Earth's environment, telecommunication systems, etc.). They are urgent for the unification of the world community, the transition to a new quality of the process of space exploration aimed at the survival and development of mankind in the paradigm of the ultimate strategic perspective towards the Earth's protection, terrestrial civilization and space humanity establishment.

However, the considered above system covering 4 super global projects is open and can be transformed and supplemented, for example:

a) By initiating solar space power system aimed at providing the energy for the human civilization on Earth;

b) By extracting on asteroids extraterrestrial natural resources, vital for humanity;

c) By developing the Earth's protection system under new types of threats and counteracting them (for example, dangerous effects and consequences of superpowerful magnetic storms due to the increased activity of the Sun, etc.);

d) By searching for extraterrestrial life, inhabited exoplanets, extraterrestrial civilizations for the purpose of the further expansion, contact making, protection, etc.

A new wave of space environment exploration is arising in the world community, the boundaries of the space activity branch are expanding, a transition to new space technologies, aimed at increasing safety and efficiency, is being made.

The contemporary mankind is bound to reach a new level of space exploration through the development and implementation of the common super global strategy, synthesizing upto-date super global projects and efficient clean technologies in the paradigm of balanced sustainable "green" development on Earth and in space.

\section{Environmentally Friendly Technologies and Space Exploration Projects}

The problem of research, development and implementation of environmentally friendly space technologies and projects tends to be rather complex and of the interdisciplinary character. The situation is complicated by the lack of established terminology system and the criteria for assessing the environmental "cleanliness" of the technologies and projects (space and others), as well as by their rapidly increasing number.

The total number of issued patents in the world is more than 70 million (according to: [Dykov, 2014: 35]), however, it is not stated how many of them refer to eco-friendly issues. In the first approximation, there are several thousands of such documents, among them about 1000 cover space technologies (according to the author's study).

There is a significant potential for the greening of machinery and activities due to the transition towards eco-friendly technologies and projects because a great number of them have been already developed and are ready to be applied.

${ }^{15}$ See [Asgardia — The Space Nation. Website; Strategic Public Movement “Russia 2045” Website; Krichevsky, 2017a]. 
Let us emphasize and give six important examples for approximately 100-year time period (throughout the 20-21 $1^{\text {st }}$ centuries), encompassing various aspects of environmental cleanliness.

1. Friedrich Zander (1887-1933), scientist, design engineer, inventor, Russia / USSR. In 1909 (according to other sources, in 1911) he introduced the idea to use solid construction materials of interplanetary spacecraft as fuel. Zander also developed the project of an interplanetary ship with the possibility of such a technology implementation, made a description of it and an application for his invention (1923-1924) [Zander, 1988]. However, the project has not been implemented. It is characterized by the following peculiar aspects: the environment could be polluted when burning metal constructions, etc. (See [Mikhailov, 1999: 80]).

2. Herman Potočnik (pseudonym Herman Noordung), (1892-1929), engineer, Austria. In 1928, he set forth the idea of "The Wheel of Life" - a project of a rotating wheel space station with artificial gravity, a kind of a living module, a rotating toroidal object [Noordung, 1935]. The project has not been implemented.

3. Valery Burdakov (1934-2014) and others, Russia. In 1995, he pioneered the issue of nanofuel - The program was patented in Russia in 1999. The project has not been implemented [Burdakov, 2010].

4. Yury Kuznetsov (born in 1951) and others, Russia. In 1994, he introduced the project of the reusable winged accelerator of the first stage of the carrier rocket. It was patented in Russia in 1999. The project "Baikal" has not been implemented. [Patent 2148536 RF, 2000].

5. Vladimir Leonov (born in 1949), Russia. In 1996, he originated and patented (2001) the idea of a quantum spacecraft engine. [Patent 2185526 RF, 2002]. The project has not been implemented.

6. Elon Musk (born in 1971), businessman, SpaceX Corporation, USA. He set forth the issue of the reusable launch system and developed the Falcon 9 rocket, the first orbital class rocket capable of reflight. In 2015 - the first successful landing of the stage; in 2017 - the first successful reuse [SpaceX Corporation Website].

The examples, given above, reveal the role of scientists, inventors, practical engineers in the field of designing and implementation of green technologies, projects, and emphasizes the idea of significant contribution and potential of Russian developers. Unfortunately, the real life shows that most of these ideas and projects have failed to be put into practice. According to the data currently available, less than $10 \%$ of patents are applied in the world. In fact, in the $21^{\text {st }}$ century it happens that a significant number of new technologies are not patented, they are designed, exist somewhere and are probably implemented as a commercial secret, etc.

\section{List of Emerging and Promising Environmentally friendly Technologies and Projects}

Summarizing the available information which encompasses ideas, patents and projects, it can be arranged and presented as follows:

1. The latest rocket technologies: new fuel (so-called "green", non-toxic, nanofuel, etc.), modern engines (laser, plasma, etc.) and carrier rockets, reusable launch space systems capable to return to Earth, single-stage launch vehicles, etc.

2. The minimization technologies, waste processing and cleaning systems of the environment.

3. Non-jet spacecraft and non-rocket space technologies and equipment, operated on the newly discovered physical principles - gravitational, quantum effects, etc (in the long term perspective). 
4. Noiseless (outside and inside) aircraft.

5. "Waste-free" spacecraft.

6. Green full life cycle of space equipment and activity.

7. Fundamentally newly developed technologies aimed at human life support and safety in space.

8. Space Earth-Moon elevator, space transport systems, etc.

9. Solar space power stations

10. Specific projects for the space field improvement and transition to the best available technologies, clean and green equipment (for example: Clean Space Initiative initiated by European Space Agency (European Union), 2013 [Clean Space]).

The list made is not full and could be widened.

The central problem to be resolved then is the process of successful implementation of fundamentally new technologies, their expertise, quality assessment and management.

\section{Conclusion}

1. Three distinct time periods in the history of the Space Age have been identified.

2. The concept of "space" has been classified by substantiating the tree-leveled structure of the "global" phenomenon: 1) planetary-global; 2) super global; and 3) universallyglobal.

3. The notion of "super global space exploration project" has been introduced.

4. A new cosmic wave of activity is rising in the world; practical implementation of super global projects begins.

5. The concept of further space exploration is proposed, which includes four interrelated super global projects

(Earth Protection System from Asteroid and Comet Threat; Moon Exploration; Mars Exploration; and Cosmic Humanity) as the basis of the long-term mankind space strategy has been studied.

6. The idea that super global space exploration projects can serve as an attractor and socalled superhighway for the sustainable civilization development has been emphasized.

7. It has been substantiated that successful implementation of super global space exploration projects becomes possible due to the transition towards an emerging technological model encompassing fundamentally new, efficient and clean technologies.

8. The given examples of environmentally friendly space technologies and projects of the $20^{\text {th }}-21^{\text {st }}$ centuries have proved to be topical.

9. The list encompassing emerging and promising environmentally friendly (clean and green) space technologies and projects has been worked out.

10. It has been shown a high potential for space technology greening, a great number of ready-developed eco-projects, necessary to be efficiently managed.

11. It has been highlighted the efficiency and relevancy of anticipatory philosophical reflection and interdisciplinary examination of recent projects and technologies in space exploration and study fields aimed at overcoming emerging challenges and topical issues of the space mankind future.

\section{[0] References}

Asteroid and Comet Attack Threat: Yesterday, Today, and Tomorrow. Ed. by Boris Shustov and Lydia Rykhlova. Moscow: FIZMATLIT, 2010. 
Burdakov, Valery. Mono? Nano! Russian Space. 10, 2010: 24-27.

Clean Space / Green technologies // Website of ESA. Available at: http://www.esa.int/Our Activities/Space_Engineering/Clean_Space/Green_technologies

Cosmonautics of the $21^{\text {st }}$ century: Attempt of the Forecast of Development till 2101. Ed. by Boris Chertok. Moscow: RTSoft, 2010.

Dykov, Mikhail; Kravets, Alla; Korobkin, Dmitry, and others. Automated Decision-Making System while Patent Application Examination. News of Volgograd State Technical University. Issue. 20, № 6, 2014: 35-41.

Futurology. XXI Century: immortality or a global catastrophe? Alexey Turchin and Mikhail Batin. Moscow: Binom. Knowledge Laboratory, 2013.

Galimov, Eric. Concepts and Failures: Fundamental Space Environment Research in Russia of the Last Twenty Years. Twenty Years of Unsuccessful Efforts. Moscow: Editorial URSS, 2010.

Gatland, Kenneth, Mitchell Sharp, David Skinner. Space Technology: Illustrated Encyclopedia. Moscow: Mir, 1986.

Global Future 2045. Convergent Technologies (NBICS) and the Evolution of the Transhumanist. Ed. by Prof. David Dubrovsky. Moscow: Ltd "Publishing House of the IBA", 2013.

Grishin, Sergey and Leonid Leskov. Industrialization of Space: Problems and Perspectives. Moscow: Nauka, 1987.

Kasavin, Ilya. Megaprojects and Global Projects: Science between Utopia and Technocracy. Issues of Philosophy. 2015: 40-56.

Krichevsky, Sergey. Aerospace Activities: Interdisciplinary Analysis. Moscow: LIBROKOM, 2012.

Krichevsky, Sergey. The Cosmic Future of Man and Mankind: Problems and Prospects. Russian Journal of Philosophical Sciences. 9, 2013: 38-43.

Krichevsky, Sergey. "Green" Astronautics for Future of Mankind. Earth and the Universe. 6, 2014: 34-42.

Krichevsky, Sergey. The Evolution of Technology, "Green” Development and the Foundation of the General Theory of Technology. Philosophy and Cosmology. 14, 2015: 120-139.

Krichevsky, Sergey. "Greening” Outer Space Environment. Energy, Economy, Technology, Ecology. 10, 2016: 61-63.

Krichevsky, Sergey. A Management Concept of the Technosphere's Evolution. Philosophy and Cosmology. 18, 2017: 153-164.

Krichevsky, Sergey. Cosmic Humanity: Utopia, Realities, Prospects. Future Human Image. 7, 2017a: 50-70.

Lem, Stanislav. The Sum of Technology. Moscow: Mir, 1968.

Mikhailov, Vladimir. Rocket and Space Pollution: History of Origin. Moscow: Nauka, 1999.

Noordung, Herman. The Problem of World Space Travel. Leningrad, 1935.

Pakhomova, Nadezhda, Richter Knut, and Grigory Malyshkov. Structural Transformations under "Green" Economy Development Conditions: Challenges for the Russian State and Business. Problems of Modern Economy. 3, 2012: 7-15.

Patent 2148536 RF, IPC B64G1/14. Reusable First Stage Launch Vehicle Accelerator / Kiselev A.I., Kuznetsov Yu.L., Medvedev A.A. and others; Applicants and Patent Holders: the State Space, Science and Industry Centre named after M.V. Khrunichev, Scientific and Production Association "Molniya"; initiat. on October 26, 1999; publ. on May 10, 2000. - Bul. № 13. - 17 p. 
Patent 2185526 RF, IPC F03H5/00. The Method of Thrust Producing in Vacuum and the Field Engine for a Spaceship (options) / Leonov V.S.; Applicants and Patent Holders: Leonov V.S., Pilkin V.E.; initiat. on May 21, 2001; publ. on July 20, 2002. - Bul. № 20. $31 \mathrm{p}$.

Piloted expedition to Mars. Head ed. Anatoly Koroteev. Moscow: Russian Academy of Cosmonautics named after K.E. Tsiolkovsky, 2006.

Predicting the Future: A New Paradigm. Ed. by Gleb Fetisov and Valentina Bondarenko. Moscow: "Economics", 2008.

Preliminary National Standard of PTT 22-2014. The Best Available Technologies. Concepts and Definitions. Official edition. Moscow: Standartinform, 2014.

Rozin, Vadim. Technology as a Time Challenge: Study, Concept and Types of Technology. Philosophy and Cosmology. 19, 2017: 133-141.

Space Age 2001. Forecast for 2001. [trans. from English] ed. by Vasily Yemelyanov. Moscow: Mir, 1970.

Tsiolkovsky, Constantine. Industrial development of space. Moscow: Mechanical Engineering, 1989.

Ursul, Arkady and Tatiana Ursul. Universal (global) evolutionism and global research. Philosophical Thought. 1, 2012: 46-101. Available at: http://e-notabene.ru/fr/article_116. html

Ursul, Arkady and Tatiana Ursul. Global-cosmic revolution in science. Philosophical Thought. 2, 2017: 26-45. Available at: http://e-notabene.ru/fr/article 21876.html

Vlasov, Mikhail and Sergey Krichevsky. Ecological Threat of Space Activity. Analytical Review. Moscow: Nauka, 1999.

Website «Asgardia — The Space Nation». Available at: https://asgardia.space/

Website of NASA (USA). Available at: https://www.nasa.gov/

Website of the Roscosmos State Corporation for Space Activities (Russian: POCKOCMOC). Available at: https://www.roscosmos.ru/

Website of the S.P. Korolev Rocket and Space Corporation Energia. Available at: https:// www.energia.ru/

Website of SpaceX Corporation, USA. Available at: http://www.spacex.com/

Website of Strategic Public Movement "Russia 2045". Available at: http://www.2045.ru/

Where are the Voyagers? // Voyagers. The Interstellar Mission. Jet Propulsion Laboratory / Website of California Institute of Technology. NASA. Available at: http://voyager.jpl. nasa.gov/where/index.html

Zaitsev, Anatoly. Earth Will Need a "Citadel”. Military Industrial Courier (August 15, 2007). Available at: https://vpk-news.ru/articles/3205

Zander, Frederick. Problems of interplanetary flights. Moscow: Nauka, 1988. 